\title{
Correction to: Paradoxical Activation in the Cerebellum During Language fMRI in Patients with Brain Tumors: Possible Explanations Based on Neurovascular Uncoupling and Functional Reorganization
}

\author{
Nicholas S. Cho ${ }^{1}$ Kyung K. Peck ${ }^{1,2} \cdot$ Zhigang Zhang $^{3} \cdot$ Andrei I. Holodny $^{1}$ \\ Published online: 3 October 2019 \\ (C) Springer Science+Business Media, LLC, part of Springer Nature 2019
}

Correction to: The Cerebellum (2018) 17: 286-293

https://doi.org/10.1007/s12311-017-0902-5

The original version of this article unfortunately contained mistake in Funding information section.

The authors hereby publish the correct Funding information.

Funding information This study was funded by the National Institute of Health (NIH), NIH-NIBIB 1R01EB022720-01 (Makse and Holodny, PI's) and NIH-NCI U54 CA137788 / U54 CA132378 (Ahles, PI).

Publisher's Note Springer Nature remains neutral with regard to jurisdictional claims in published maps and institutional affiliations.

The online version of the original article can be found at https://doi.org/ 10.1007/s12311-017-0902-5

Kyung K. Peck

peckk@mskcc.org

1 Department of Radiology, Memorial Sloan Kettering Cancer Center, New York, NY 10065, USA

2 Department of Medical Physics, Memorial Sloan Kettering Cancer Center, New York, NY 10065, USA

3 Department of Epidemiology and Biostatistics, Memorial Sloan Kettering Cancer Center, New York, NY 10065, USA 